\title{
Integral tow-lifting construction technology of a tensile beam-cable dome"
}

\author{
Ming-min DING ${ }^{\dagger 1}$, Bin LUO ${ }^{\dagger 1,2,3}$, Zheng-xing GUO ${ }^{1,2,3}$, Jie PAN $^{4}$ \\ ( ${ }^{1}$ Department of Civil Engineering, Southeast University, Nanjing 210096, China) \\ $\left({ }^{2}\right.$ National Pre-stressed Engineering Center of China, Nanjing 210096, China) \\ $\left({ }^{3}\right.$ Key Laboratory of Concrete and Pre-stressed Concrete Structures of the Ministry of Education, Nanjing 210096, China) \\ $\left({ }^{4}\right.$ Wuxi Architectural Design \& Research Institute Liability Co. Ltd., Wuxi 214001, China) \\ †E-mail: dingmingmin19890210@gmail.com; seurobin@seu.edu.cn \\ Received June 24, 2015; Revision accepted Oct. 8, 2015; Crosschecked Nov. 10, 2015
}

\begin{abstract}
A cable dome is a form of cable-strut tensegrity structure, which is popular for long span membrane roof structures. However, there is an opportunity for its major development for a wider range of applications if rigid roof cable dome structures can be achieved. In this paper, we propose the tensile beam-cable dome (TBCD), a new type of space structure based on the features of the cable dome. By changing the ridge cables to hinged tensile beams, a structure can easily be covered with a rigid roof. We introduce its configuration and mechanical characteristics, and put forward four categories of this structure with hinges set at different locations on the tensile beams. In addition to achieving the aims of tow-lifting and tensioning construction, the integral tow-lifting method is presented for TBCD, and the nonlinear dynamic finite element method (NDFEM) of form-finding analysis is introduced for the overall construction analysis. For integral tow-lifting construction, the mechanism hinges should be set at the middle of the tensile beams to make the tensile beam grid into a mechanism system. Through construction analysis of seven mechanism hinge distribution modes, the modes with mechanism hinges set only on the middle or inner tensile beams were optimal.
\end{abstract}

Key words: Tensile beam-cable dome (TBCD), Integral tow-lifting construction, Construction analysis, Mechanism hinge doi: 10.1631 jzus.A1500189

Document code: A

CLC number: TU393.3

\section{Introduction}

The cable dome system originates from Fuller's patent of 1962 (Fuller, 1975), in which he proposed a triangular cable net with compressive struts hinging on it. The first cable dome was designed by Gei-

\footnotetext{
${ }^{\ddagger}$ Corresponding author

* Project supported by the National Key Technology R\&D Program of China (No. 2012BAJ03B06), the National Natural Science Foundation of China (No. 51308105), the Priority Academic Program Development of Jiangsu Higher Education Institutions (PAPD), and the Fundamental Research Funds for the Southeast University (No. KYLX 0152, SJLX 0084), China

(D) ORCID: Ming-min DING, http://orcid.org/0000-0003-0478-4618; Bin LUO, http://orcid.org/0000-0001-9455-1847

(C) Zhejiang University and Springer-Verlag Berlin Heidelberg 2015
}

ger (Geiger et al., 1986) for the Seoul Olympics gymnastics and fencing halls in 1986, and cable domes have subsequently been widely used in many large-span structures. Currently, the largest is the Georgia dome designed for the Atlanta Olympics (Levy, 1994).

A traditional cable dome is composed of ridge cables, oblique cables, ring cables, and struts. In contrast to masts (Juozapaitis et al., 2008; Belevičius et al., 2013), an initial pre-stress in the cables and struts gives the cable dome rigidity, making it a structure with the ability to resist external loads (Wang et al., 2010). The roofing materials of cable domes can be divided into two categories: a flexible roof with tensioned membranes and a rigid roof with glass or thin 
steel plates. Up to now, most existing cable domes have been covered with tensioned membranes.

Tensioned membranes have the advantages of being lightweight and semi-transparent, and having strong span ability. However, the high cost, the large deformation, the low bearing capacity, the poor thermal insulation performance, and their poor antipollution performance make them unable to meet the demands of architecture today.

Meanwhile, traditional rigid roofing materials, such as glass panels and color steel plates, can meet those demands, and encourage the adaptation of cable domes. Cai et al. (2013) pointed out that a rigid roof lacks good in-plane stiffness. Therefore, substructures are needed to improve its span.

An improved scheme (Luo and Guo, 2012) was proposed for putting a single-layer reticulated shell on the top of struts, and this was successfully applied in Wuxi New District Science \& Technology Communication Center (Guo et al., 2010a; 2010b). Vizotto (2010) proposed a computational model of freeform shell generation in the design of roof structures that relies on the optimized behavior of the membrane theory of thin shells; this offers a low cost, fast, and relatively easy design solution. Ario et al. (2013) designed a new emergency bridge called a Mobilebridge $^{\mathrm{TM}}$ and obtained a shape-optimization structure for this new type of deployable bridge. Luo et al. (2012) put forward a new kind of structure with an orthogonal single-layer cable net added on the ridge cables to support a rigid roof, which was used in China for the Taiyuan Coal Trading Center.

Traditional on-site construction of a cable dome requires five steps: (1) assembly of a temporary tower in the center of the field and placing the inner tensile ring on it; (2) installation of connectors on the ridge cables, and then connecting the ridge cables with the inner tensile ring and the outer compressive ring; (3) lifting struts, radial cables, and ring cables to the designed location, and connecting them to the ridge cables; (4) establishing the pre-tension and forming the structure by tensioning the cables or supporting the struts; (5) installation of the membrane roof. However, this method is expensive and extends the construction period because of the installation of the temporary tower. In this case, lifting construction methods and developable construction methods could be applied on cable dome structures. Li et al. (2003) used an electro-hydraulic proportion- al control system to raise a $6075-\mathrm{t}$ roof frame to the height of $26.5 \mathrm{~m}$.

Based on the idea of supporting and lifting, Guo et al. (2010a; 2010b) proposed a new method called tower lifting and accumulative installation for cable domes. This method also contains five steps: (1) assembly of a temporary lifting tower in the center of the field; (2) installation of all the components in the center of the field and connection of the ridge cables with the outer compressive ring; (3) connection of the top part of the tower with the inner tensile ring by lifting cables and lifting the whole structure to the designed location; (4) establishment of the pretensions and forms of the structure by tensioning the cables or supporting the struts; (5) installation of the roof system. This method needs less time for working high above the ground, and makes construction less dangerous and more efficient.

Before tensioning, the cable-strut system is a mechanism; after tensioning it is a form with structural rigidity. During the construction process, the cable-strut system changes from a non-stress state in the beginning to a low-stress overhanging state and, finally, reaches a high-stress formed state. Thus, form-finding, which decides the initial pre-tension and shape of a cable dome, is necessary.

There has been extensive research on the formfinding of cable nets and tensegrity structures. Schek (1974) proposed the force-density method for the form-finding of tensile structures. Vassart and Motro (1999) expanded this method in symbolic forms to a search for new configurations. Hangai and Wu (1999) employed the analytical method of hybrid structures consisting cables and rigid roof. A dynamic relaxation method was proposed by Motro et al. (1987), and has been reliably applied to tensile structures (Barnes, 1999). Ohsaki and Kanno (2003) made the form-finding analysis of cable domes under nonlinear mathematical calculation into programming problems. Masic et al. (2005) and Zhang and Ohsaki (2006) put forward new methods using force density formulations.

Dong and Luo (2002) and Shen and Zhang (2002) proposed the nonlinear force method for the space truss with mobile mechanisms to solve the coupling problem of mechanism displacement with elastic deformation, and then put forward the nonlinear force method (NFM) (Luo and Shen, 2004). Luo (2010) from Southeast University put forward a new 
form-finding method based on the nonlinear dynamic finite element (NDFEM).

Among these methods, the dynamic relaxation method converts the static problem into a dynamic problem using a virtual mass and a viscous damping force. The structure is dispersed into virtual particles with virtual masses that are located at the spatial node position. Under an unbalanced force, these dispersed virtual particles move along the unbalanced force direction macroscopically to reduce the overall unbalanced force in the structure. During the iterative procedure, motion equations of single particles are built to find the result. However, the NDFEM needs to build nonlinear finite element motion equations for the whole structure to simulate the overall vibration. The NDFEM is stable in analysis, has good structural integrity when the total kinetic energy peaks, and is more efficient in many ways.

This paper addresses several key issues of rigid roof cable domes. A new structure called a tensile beam-cable dome (TBCD) is presented firstly, followed by the configuration features and mechanical characteristics of this structure. An efficient construction method, the integral tow-lifting method, is then presented to achieve installation and tensioning construction for this structure. A detailed introduction of NDFEM is introduced and tested in a sixmeter scale model. Meanwhile, mechanism hinges on tensile beams are needed for the integral towlifting construction, making the whole structure a mechanism system, and the optimal distribution modes of those mechanism hinges are summarized in this paper.

\section{Tensile beam-cable dome (TBCD)}

\subsection{Configurations of TBCD}

If the ridge cables of the traditional cable dome are replaced by hinged beams that can bear both tensile and flexural effects, then a new structure called a tensile beam-cable dome is created. TBCD consists of oblique cables, struts, ring cables, and tensile ridge beams. In addition, all the joints between tensile beams and other members are hinged, which is helpful in increasing the proportion of axial tensile stress during the construction process, and can improve the stability of whole structure. The details are shown in Fig. 1.
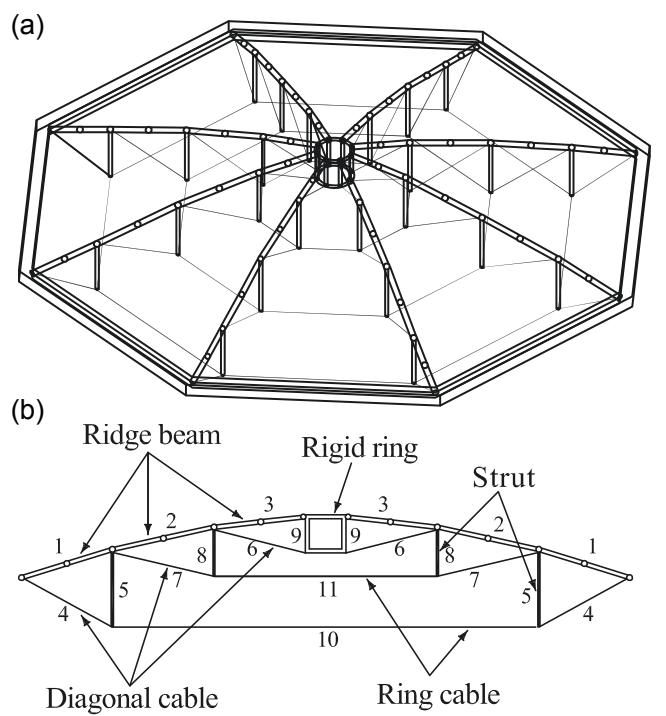

Fig. 1 Components of tensile beam-cable dome (a) Perspective view; (b) Section view. 1: outer tensile beam; 2: middle tensile beam; 3: inner tensile beam; 4: outer oblique cable; 5 : outer strut; 6 : inner oblique cable; $7:$ middle oblique cable; 8 : middle strut; 9: inner tensile ring; 10: outer ring cable; 11: inner ring cable

\subsection{Distribution of TBCD}

The hinges on tensile beams can be divided into two kinds: structure hinges and mechanism hinges. Structure hinges are set at the end of tensile beams and exist in normal use, while mechanism hinges are set at the middle of tensile beams and exist only during construction. Settings of hinges are flexible. According to the location of structure hinges and mechanism hinges, TBCD can be divided into four categories: Non-hinge TBCD (NTBCD), Single-hinge TBCD (STBCD), Double-hinge TBCD (DTBCD), and Three-hinge TBCD (TTBCD). The details are shown in Fig. 2 and Table 1.

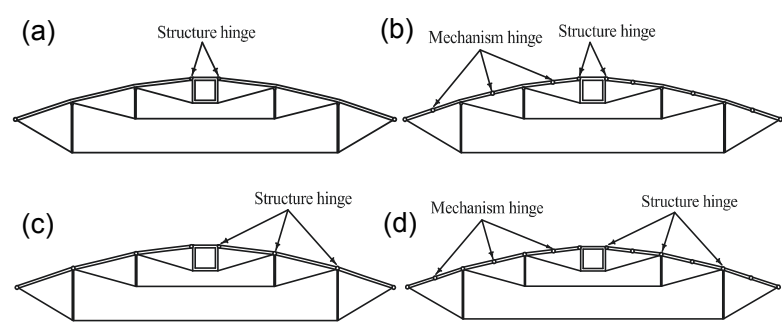

Fig. 2 Section view of TBCD

(a) Non-hinge TBCD; (b) Single-hinge TBCD; (c) Doublehinge TBCD; (d) Three-hinge TBCD 
Table 1 Classification of TBCD

\begin{tabular}{cccc}
\hline Category & $\begin{array}{c}\text { End of tensile } \\
\text { beams }\end{array}$ & $\begin{array}{c}\text { Middle of } \\
\text { tensile beams }\end{array}$ & Support \\
\hline NTBCD & Non-hinged & Non-hinged & Hinged \\
STBCD & Non-hinged & Hinged & Hinged \\
DTBCD & Hinged & Non-hinged & Hinged \\
TTBCD & Hinged & Hinged & Hinged \\
\hline
\end{tabular}

TTBCD has enough mechanism hinges to avoid large local bending stresses, whose mechanical characteristics are similar to traditional cable dome. However, under a rigid roof, large tension forces are needed to reduce the large local deformation that occurs at the location of the mechanism hinges. An ideal TBCD should have both large stiffness overall and small deformations locally. The locations of the tensile beam hinges set the mechanical characteristics of TBCD to some extent, and thus, the design and static tests (Xu et al., 2014) of hinge joints are important.

\subsection{Advantages of TBCD}

Traditional cable domes are made of cables and struts, their stiffness is formed by the building of pre-stress (Zhang et al., 2007). The level of prestress will not only affect the geometric configuration, but also determine the serviceability and load bearing capacity of traditional cable domes, which leads to a poor local stability (Kmet and Mojdis, 2013; 2015) during construction.

In contrast, due to the adding of tensile beams, TBCDs have enough bending stiffness to resist large local deformation. Thus, cable slack during the construction process consists of the initial state without stress, a low stress relaxation state during erection, and a high tensile stress state after the dome shape is formed. Furthermore, tensile beams can bear both tensile effects and flexural effects, which makes it easy for convergence and convenient to lay rigid roofing materials on. Thus, the TBCD has the advantages of both traditional cable domes and suspendomes (Gao and Weng, 2004).

\section{Integral tow-lifting construction technolo- gy for TBCD}

The integral tow-lifting construction method includes assembly at a low altitude, tow-lifting at a moderate altitude, and tensioning to form at a high altitude. The key four steps are: 1) installing the outer compressive ring at the designed position, and then assembling the inner tensile ring, the hinged tensile beams, and the tow-lifting tool cables near the ground; 2) assembling oblique cables, ring cables, and struts at a low altitude followed by subsequent lifting and towing; 3) lifting the inner tensile ring and towing the outer tensile beams alternately by tool cables (towing cables and lifting cables) until the outer tensile beams are connected to the outer compressive ring; 4) finally, tensioning the outer oblique cables simultaneously to form the whole structure. The specific construction steps are shown in Fig. 3.
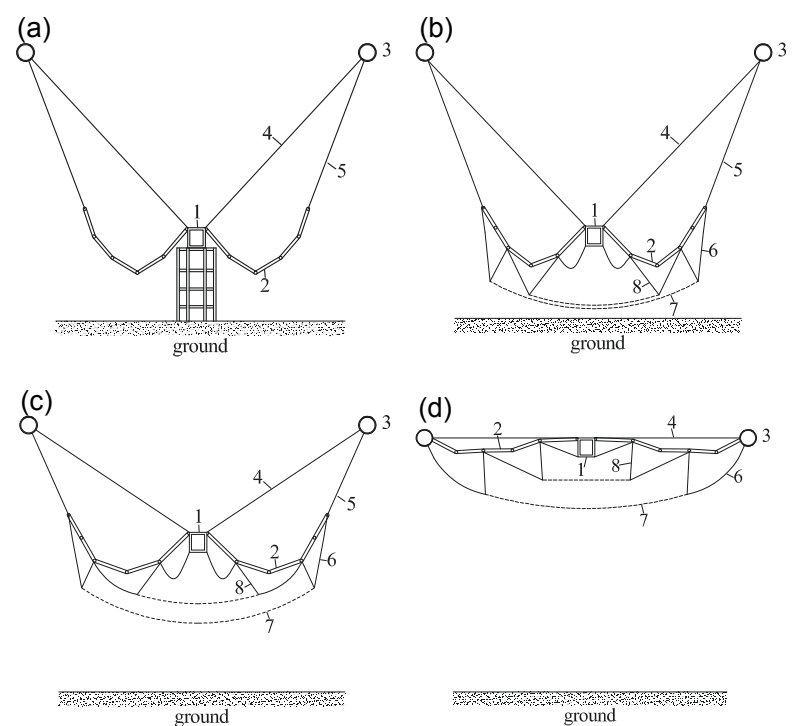

(d)
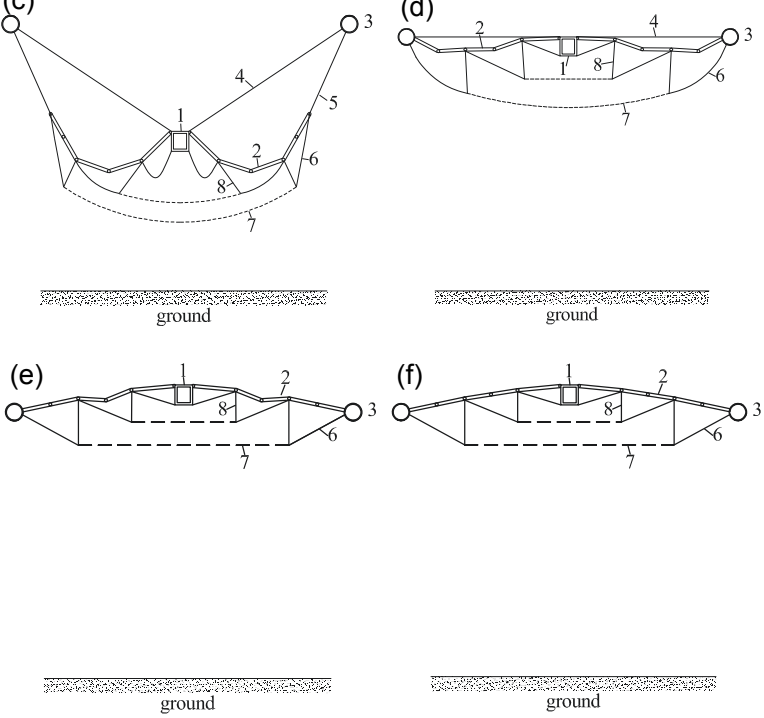

Fig. 3 Integral tow-lifting construction process for TBCD

(a) Install inner tensile ring, tensile beams, and tool cables;

(b) Install cables and struts; (c) Tow and lift alternately;

(d) Connect tensile beams with the compressive ring;

(e) Shorten the tensioning cables; (f) Tension the outer oblique cables and form the structure. 1: inner tensile ring; 2: tensile beam; 3: outer compressive ring; 4: lifting tool cable; 5: towing tool cable; 6: oblique cable; 7: ring cable; 8: compressive strut 
Integral tow-lifting construction technology uses the outer compressive rings as tow-lifting brackets. Furthermore, the small lifting force, the few working aloft, and the high efficiency of tensioning make this method convenient in use. However, it must emphasis that the tensile beam grid must maintain a " $\omega$ " shape during the whole process. That is vital for success.

In addition, in order to accomplish the assembly (tow-lifting and tensioning) processes on the construction site, we introduced tow-lifting and tensioning equipment, which is illustrated in Fig. 4.

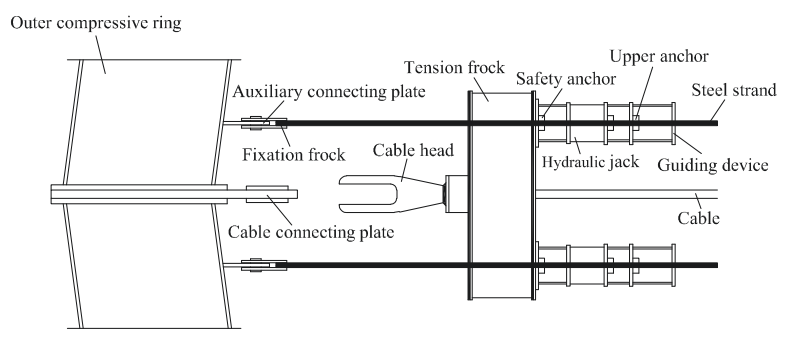

Fig. 4 The tow-lifting and tensioning equipment

A set of tow-lifting and tensioning equipment is mainly made up of two hydraulic jacks, two steel strands, one tension frock, and two auxiliary connecting plates. During the tow-lifting and tensioning process, a set of equipment is set at the outer side of a cable. By tensioning the steel strands, the tensioning force built by hydraulic jacks is transferred to the outer compressive ring, and the cable head of the oblique cable or tool cable moves slowly towards the support. Finally, the cable head is connected with the connecting plate of the outer compressive ring, and the equipment is removed.

\section{Nonlinear dynamic finite element method (NDFEM) for form-finding analysis}

Due to the large displacement, mechanism deformation, and cable slackness during construction, a large difference in configuration occurs between the construction stages and the formed state of TBCD. The construction process is dynamic, but the whole system is in a static equilibrium state at a certain moment. Therefore, the whole construction process can be divided into several static cases.

\subsection{Analytic logic and specific steps}

The NDFEM method is used to determine the static equilibrium state of the tensile-beam and cable-strut systems during construction. By introducing a virtual inertia force and a viscous damping force, the equations of motion are established, which transform static problems into dynamic problems that are easy to solve. Furthermore, by iterative updating of the configuration of the tensile-beam and cable-strut systems, the dynamic equilibrium state gradually converges to the static equilibrium state. Thus, a tensile-beam and cable-strut system is in an unbalanced static state before the analysis, in a dynamic balanced state during the analysis, and reaches a static balanced state after convergence. The analysis includes the following steps: establishing an initial finite-element model; nonlinear dynamic finite element analysis and updating of the model when the total kinetic energy reaches its peak; dynamic analysis again until the configuration converges; and nonlinear static analysis of the converged model to verify the static equilibrium state. For TBCD, it is convenient for analysis that hinged tensile beams may be modeled by spar elements. The detailed process is shown in Fig. 5.

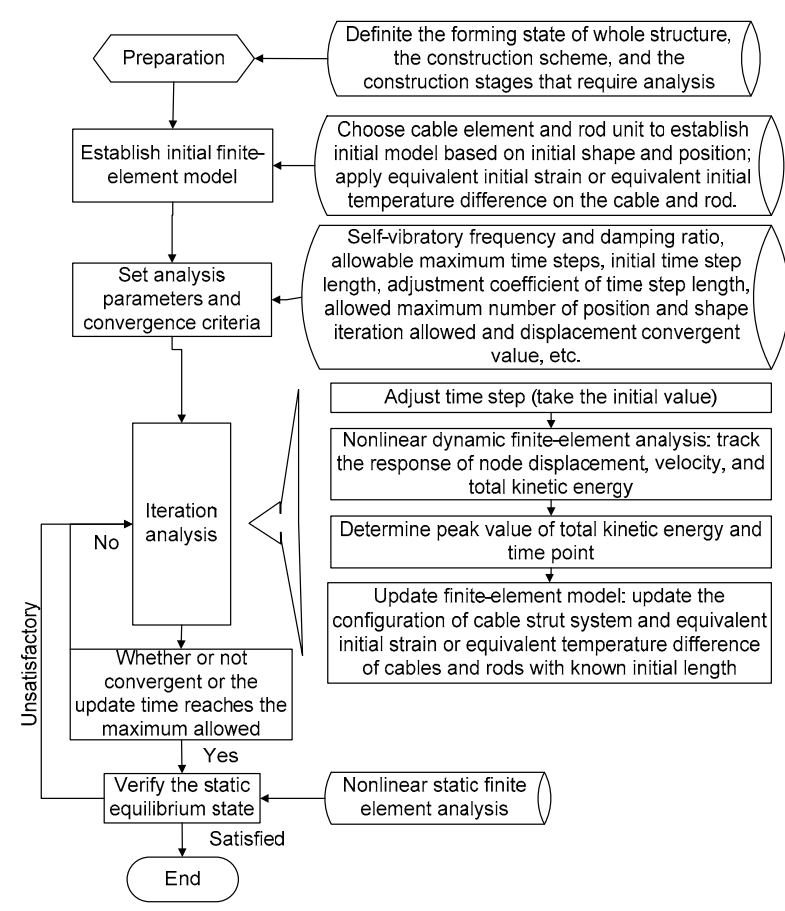

Fig. 5 NDFEM form-finding process 


\subsection{Key measures}

There are two iteration grades in NDFEM formfinding analysis, the first grade is the dynamic equilibrium iteration, and the second is the model updating iteration.

The dynamic balance equation (Eq. (1)) adopts the Rayleigh damp matrix (Eq. (4)), in which the self-vibratory frequency and damping ratio can be set virtually. When the movement direction of the tensile-beam cable-strut system is known, the motion equation of Eq. (5) should be established to accelerate the efficiency of analysis, and in which the damping force is not considered.

$$
\begin{gathered}
\boldsymbol{M} \ddot{\boldsymbol{U}}+\boldsymbol{C} \dot{\boldsymbol{U}}+\boldsymbol{K} \boldsymbol{U}=\boldsymbol{F}(t), \\
\boldsymbol{C}=\alpha \boldsymbol{M}+\beta \boldsymbol{K}, \\
\alpha=\frac{2 \omega_{i} \omega_{j}\left(\xi_{i} \omega_{j}-\xi_{j} \omega_{i}\right)}{\omega_{j}^{2}-\omega_{i}^{2}}, \\
\beta=\frac{2\left(\xi_{j} \omega_{j}-\xi_{i} \omega_{i}\right)}{\omega_{j}^{2}-\omega_{i}^{2}}, \\
\boldsymbol{M} \ddot{\boldsymbol{U}}+\boldsymbol{K} \boldsymbol{U}=\boldsymbol{F}(t),
\end{gathered}
$$

where $\boldsymbol{U}, \dot{\boldsymbol{U}}$, and $\ddot{\boldsymbol{U}}$ are the displacement vector, speed vector, and acceleration vector, respectively; $\boldsymbol{C}$ is the Rayleigh damping matrix; $\boldsymbol{F}(t)$ is the load duration vector; $\boldsymbol{K}$ is the stiffness matrix; $\boldsymbol{M}$ is the mass matrix; $\alpha$ and $\beta$ are Rayleigh damping coefficients; $\omega_{i}$ and $\omega_{j}$ are the self-resonant circular frequencies at step $i$ and step $j ; \xi_{i}$ and $\xi_{j}$ are the damping ratios that correspond to $\omega_{i}$ and $\omega_{j}$, respectively. If $\xi_{i}=\xi_{j}=\xi$, Eqs. (3) and (4) can be simplified to Eqs. (6) and (7):

$$
\begin{aligned}
& \alpha=\frac{2 \omega_{i} \omega_{j} \xi}{\omega_{j}+\omega_{i}}, \\
& \beta=\frac{2 \xi}{\omega_{j}+\omega_{i}} .
\end{aligned}
$$

The parameters in the dynamic equilibrium iteration include: the maximum number of time steps for single dynamic analysis $N_{\mathrm{ts}}$, the maximum number of dynamic iterations for one single time step $N_{\mathrm{ei}}$, the initial time step size $\Delta T(1)$, the time step size adjustment coefficient $C_{\mathrm{ts}}\left(C_{\mathrm{ts}} \geq 1\right)$, the convergence displacement value of the dynamic equilibrium iteration $U_{\text {ei }}$, the convergence displacement $U_{\text {ci }}$, and the allowable maximum number of iteration $N_{\mathrm{ci}}$. Sub- script 'ts' means time size, 'ei' means equilibrium iteration, and 'ci' means convergence of iteration.

During the process of dynamic analysis, the displacement, the velocity, and the total kinetic energy are tracked in Eq. (8). The iterative analysis strategy is listed in Table 2 and Fig. 6.

\begin{tabular}{|c|c|c|}
\hline \multicolumn{2}{|c|}{$\begin{array}{l}\text { The } m \text { th dynamic } \\
\text { analysis and the } \\
k \text { th time step }\end{array}$} & Subsequent analysis \\
\hline \multirow[t]{3}{*}{$\begin{array}{c}\text { Con- } \\
\text { vergent }\end{array}$} & $\begin{aligned} E_{k}>E_{k-1} \\
k<N_{\mathrm{ts}}\end{aligned}$ & $\begin{array}{c}\text { Continue this dynamic analysis, } \\
\text { and start the }(k+1) \text { th time step }\end{array}$ \\
\hline & $\begin{array}{c}E_{k}>E_{k-1}, \\
k=N_{\mathrm{ts}}\end{array}$ & $\begin{array}{l}\text { Renew the numerical model ac- } \\
\text { cording to the total displace- } \\
\text { ment of the } k \text { th time step, start } \\
\text { the }(m+1) \text { th dynamic analysis, } \\
\text { and adjust the time step: } \\
\Delta T(m+1)=\Delta T(m) \times C_{\mathrm{ts}}\end{array}$ \\
\hline & $\begin{array}{c}E_{k}<E_{k-1} \\
k \leq N_{\mathrm{ts}}\end{array}$ & $\begin{array}{l}\text { Find the peak value } E_{\mathrm{p}} \text { and its } \\
\text { time step } T_{\mathrm{p}} \text { from Fig. } 6 \text {, and } \\
\text { find the total displacement of } \\
\text { this time step by linear interpo- } \\
\text { lation. Then renew the whole } \\
\text { model, start the }(m+1) \text { th dy- } \\
\text { namic analysis, and adjust the } \\
\text { time step: } \Delta T(m+1)=\Delta T(m) \times \\
C_{\mathrm{ts}}\end{array}$ \\
\hline $\begin{array}{l}\text { Non- } \\
\text { conver- } \\
\text { gent }\end{array}$ & $\begin{array}{c}E_{k}=0<E_{k-1}, \\
k \leq N_{\mathrm{ts}}\end{array}$ & $\begin{array}{l}\text { Renew the numerical model ac- } \\
\text { cording to the total displace- } \\
\text { ment of the }(k-1) \text { th time step, } \\
\text { start the }(m+1) \text { th dynamic } \\
\text { analysis, and adjust the time } \\
\text { step: } \Delta T(m+1)=\Delta T(m) \times C_{\mathrm{ts}}\end{array}$ \\
\hline
\end{tabular}

$$
E_{k}=\frac{1}{2} \dot{\boldsymbol{U}}_{k}^{\mathrm{T}} \boldsymbol{M} \dot{\boldsymbol{U}}_{k}
$$

where $E_{k}$ denotes the total kinetic energy of the $k$ th time step in dynamic analysis, and $\dot{\boldsymbol{U}}_{k}$ denotes the velocity vector of the $k$ th time step.

Table 2 Iterative analysis strategy

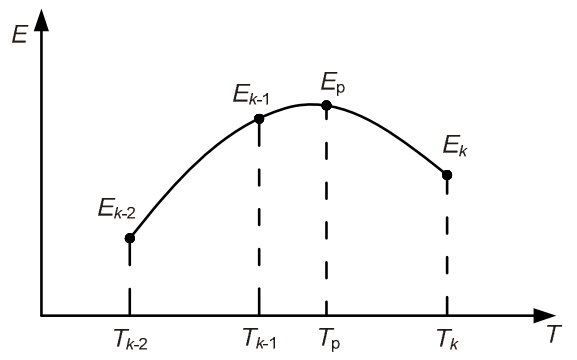

Fig. 6 Peak value of total kinetic energy and its time step 


\section{Model experiment}

\subsection{Experimental model}

To test the applicability of NDFEM in TBCD, an experiment with a three-hinge TBCD model was carried out. The experimental model is shown in Fig. 7. It was $6 \mathrm{~m}$ in span, eight pieces in radius, and three pieces in hoop (details in Table 3 and Fig. 8). A numerical model was built in ANSYS to verify the experimental results, whose parameters were the same as those of the experimental model, and the initial pre-tension of cables was built by adding an equivalent temperature difference.

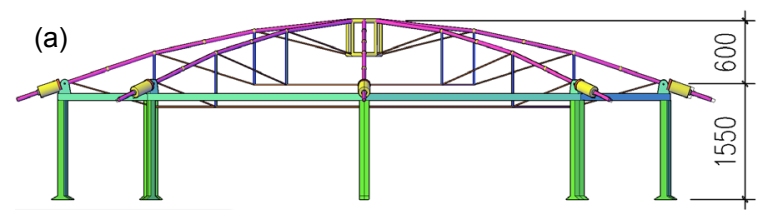

(b)

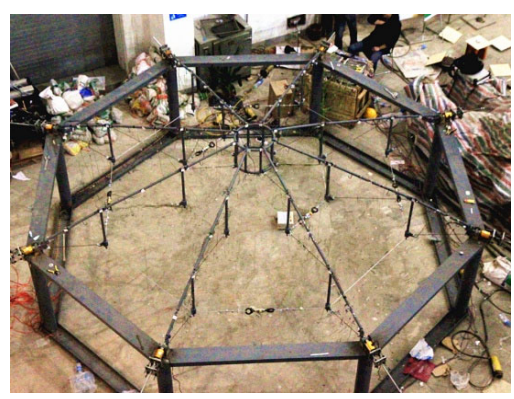

Fig. 7 Experimental model of three-hinge TBCD

(a) 3D graph of numerical model (unit: $\mathrm{mm}$ ); (b) Experimental model

Table 3 Parameters of components

\begin{tabular}{ccccc}
\hline $\begin{array}{c}\text { Compo- } \\
\text { nent }\end{array}$ & $\begin{array}{c}\text { Section } \\
\text { type }\end{array}$ & $\begin{array}{c}\text { Yield } \\
\text { strength } \\
(\mathrm{MPa})\end{array}$ & $\begin{array}{c}\text { Specifica- } \\
\text { tion }(\mathrm{mm})\end{array}$ & $\begin{array}{c}\text { Section } \\
\text { area } \\
\left(\mathrm{mm}^{2}\right)\end{array}$ \\
\hline $1 / 2 / 3$ & Steel tube & 215 & $\Phi 32 \times 3.5$ & 351.9 \\
4 & Steel wire & 928 & $\Phi 5$ & 19.6 \\
5 & Steel tube & 215 & $\Phi 30 \times 2.5$ & 235.6 \\
$6 / 7$ & Steel wire & 928 & $\Phi 5$ & 19.6 \\
8 & Steel tube & 215 & $\Phi 30 \times 2.5$ & 235.6 \\
9 & Steel tube & 215 & $\Phi 30 \times 3.5$ & 351.9 \\
$10 / 11$ & Steel wire & 928 & $\Phi 7.7$ & 46.6 \\
\hline
\end{tabular}

\subsection{Test contents and method of the experiment}

In the experiment, the key construction process had three steps: (1) setting up the temporary bracket in the center of the field, and installing the outer compressive ring at the designed position; (2) assembling the inner tensile ring, tensile beams, and cable-strut components in the non-stress state; and (3) shortening the outer tensile beams step by step until the whole structure formed. The tensioning process is divided into six stages. In each stage, lengths of the outer tensile beams are shortened by $20 \mathrm{~mm}$. The detailed sequence is shown in Fig. 9.

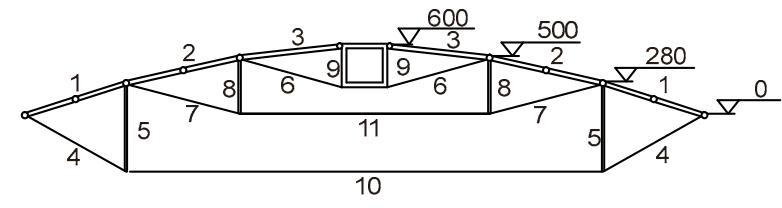

\begin{tabular}{|l|l|l|l|l|l|l|}
900 & 1000 & 900 & 400 & 900 & 1000 & 900 \\
\hline
\end{tabular}

Fig. 8 Model details and component numbers (unit: $\mathbf{m m}$ ) 1: outer tensile beam; 2 : middle tensile beam; 3 : inner tensile beam; 4: outer oblique cable; 5 : outer strut; 6 : inner oblique cable; 7: middle oblique cable; 8: middle strut; 9: inner tensile ring; 10: outer ring cable; 11: inner ring cable
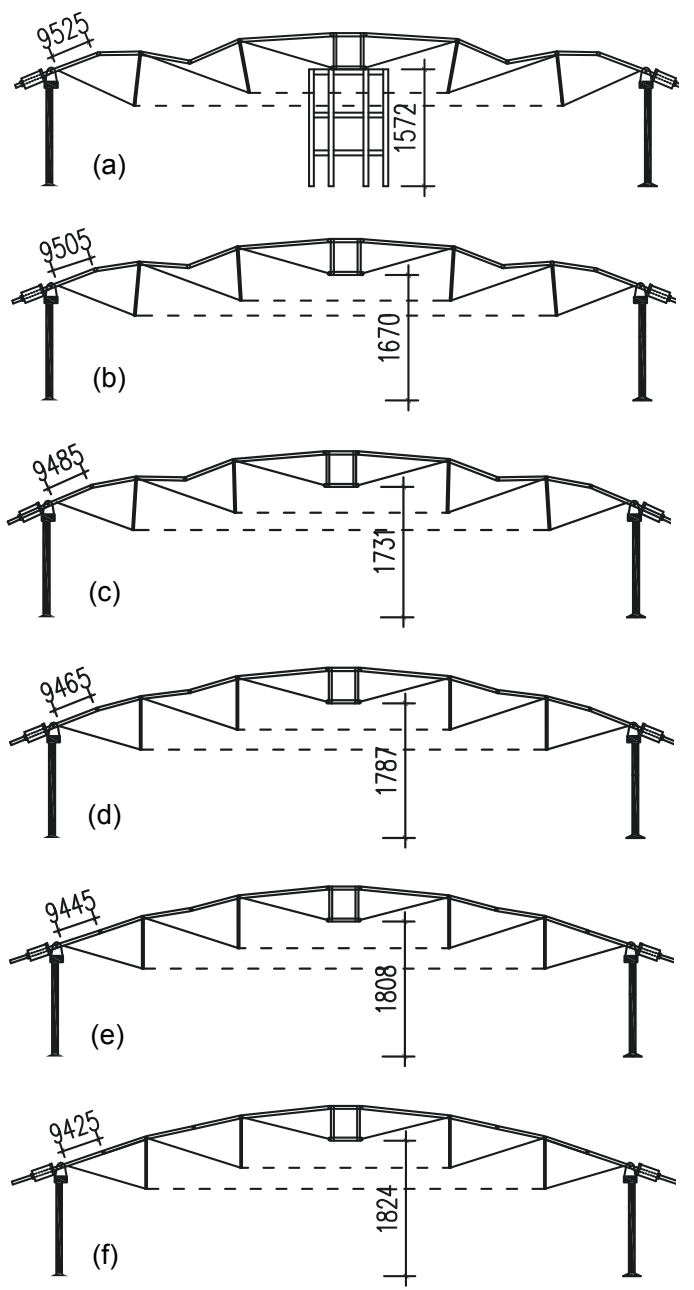

Fig. 9 Tensioning process of experimental model (unit: $\mathbf{m m}$ ) (a) Stage 1; (b) Stage 2; (c) Stage 3; (d) Stage 4; (e) Stage 5; (f) Stage 6 
The NDFEM is used to simulate this construction process. Figs. 10-12 show the average vertical displacement of the struts, the average relative deflection of the tensile beams, and the average axial force of the cables and beams, respectively. Table 4 lists the average internal force of the structure components in Stage 6. During construction, the largest difference of vertical displacement between the experimental and theoretical values is $24.3 \mathrm{~mm}$, and appears in Stage 6 at the top side of the outer struts. The largest relative deflection difference of the

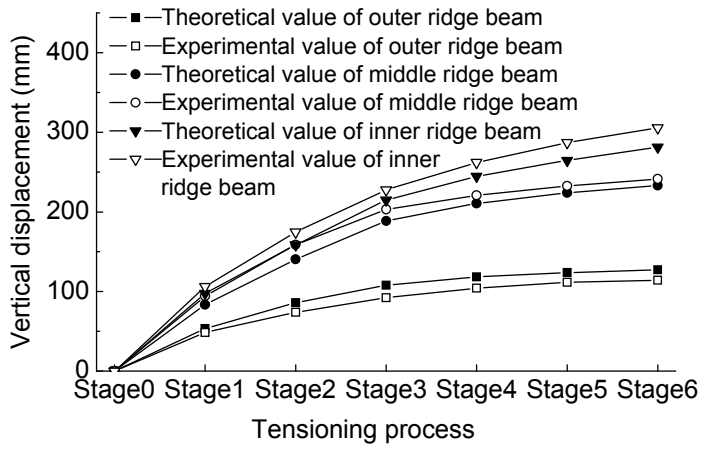

Fig. 10 Average vertical displacement

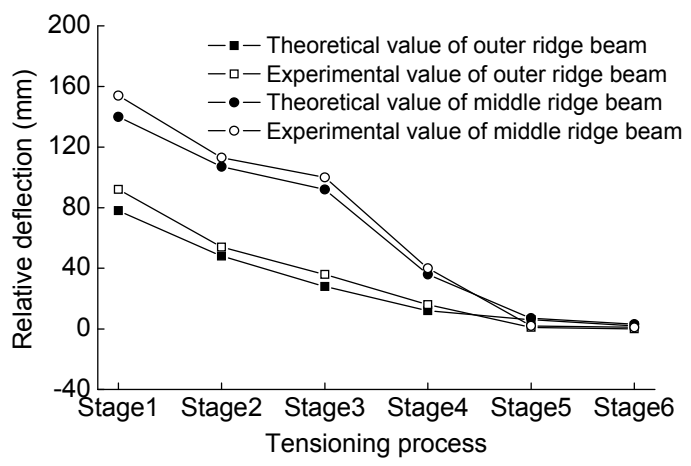

Fig. 11 Average relative deflection

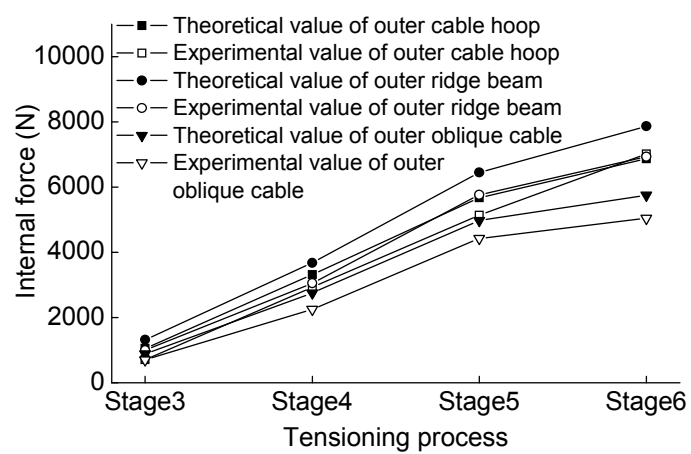

Fig. 12 Average axial force
Table 4 Average internal forces in tensile beams and cables in Stage 6

\begin{tabular}{cccc}
\hline Component & $\begin{array}{c}\text { Theoretical } \\
\text { value }(\mathrm{N})\end{array}$ & $\begin{array}{c}\text { Experimental } \\
\text { value }(\mathrm{N})\end{array}$ & $\begin{array}{c}\text { Error ratio } \\
(\%)\end{array}$ \\
\hline 1 & 7869 & 8145 & 3.5 \\
2 & 5070 & 5364 & 5.8 \\
3 & 3761 & 3429 & -8.8 \\
4 & 5756 & 5946 & 3.3 \\
6 & 6873 & 7357 & 7.0 \\
7 & 2730 & 2951 & 8.2 \\
8 & 3620 & 3883 & 7.3 \\
10 & 1438 & 1522 & 5.8 \\
\hline
\end{tabular}

tensile beams is $14 \mathrm{~mm}$, and appears in Stage 1 at the location of middle mechanism hinges. The largest force difference is $931 \mathrm{kN}$, and appears in Stage 6. In Fig. 12, the errors between experimental values and theoretical values are within $12 \%$. Thus, the NDFEM does ensure the accuracy of the construction simulation.

\section{Mechanical characteristics and hinge dis- tribution modes of TBCD}

\subsection{Mechanical characteristics of tensile beams}

Due to the pre-tension and vertical loads, ridge beams bear tensioning and bending simultaneously, which is different from flexible cables. Schematic diagrams of components under different kinds of vertical loads are set out in Figs. 13 and 14.

Under mid-span concentrated load, the flexible cable and three-hinge tensile beam are both axial tensile components. However, the two-hinge tensile beam is a kind of tensile-bending component, which makes it better to resist large deformations. The relation between load and displacement is shown as:

$$
\begin{gathered}
\Delta_{1}=\Delta_{3}=\frac{F L}{4 H}, \\
\Delta_{2}=\frac{F L^{3}}{4 H L^{2}+192 E I},
\end{gathered}
$$

where $\Delta_{n}(n=1,2, \ldots, 10)$ means the local deformation shown in Figs. 13 and 14; $E, I, F, H$, and $L$ denote the elastic modulus, the area moments of inertia, the mid-span concentrated load, the axial force, and the length of span, respectively. Thus, EI denotes the stiffness of components. 
Under uniform load, the flexible cable is only a tensile component, but the three-hinge tensile beam and the two-hinge tensile beam bear tensioning and bending simultaneously. The deformations of midspan and quarter-span are shown as follows.
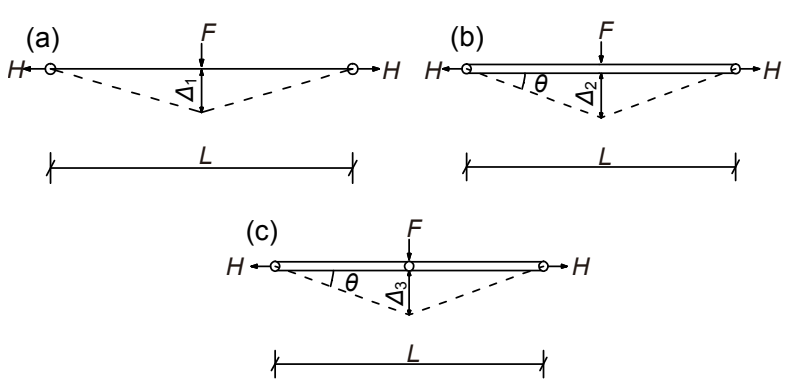

Fig. 13 Deformation of flexible cables (a), two-hinge tensile beams (b), and three-hinge tensile beams (c) under concentrated load
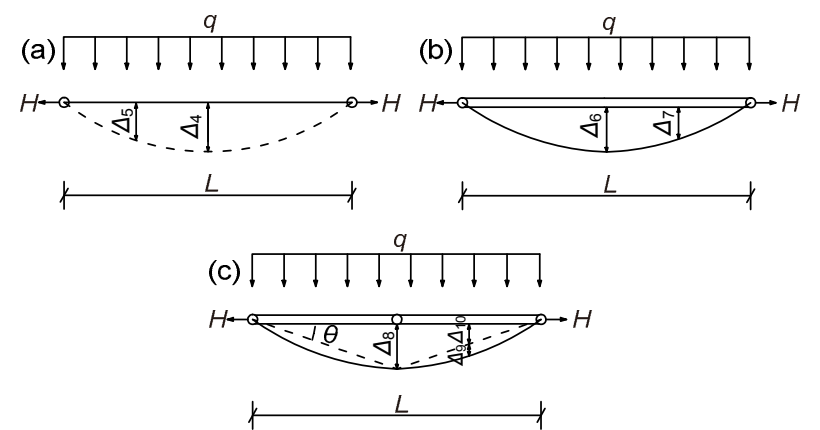

Fig. 14 Deformation of flexible cables (a), two-hinge tensile beams (b), and three-hinge tensile beams (c) under uniform load ( $q$ denotes the uniformly distributed load)

The mid-span deformation of the flexible cable is

$$
\sum M=\frac{1}{8} q L^{2}-H \Delta_{4}=0, \Delta_{4}=\frac{q L^{2}}{8 H}
$$

The mid-span deformation of the two-hinge tensile beam is

$$
\begin{gathered}
\sum M=\frac{1}{8} q L^{2}-H \Delta_{6}-\frac{384 E I \Delta_{6}}{40 L^{2}}=0, \\
\Delta_{6}=\frac{5 q L^{2}}{40 H L^{2}+384 E I} .
\end{gathered}
$$

The mid-span deformation of the three-hinge ridge beam is

$$
\sum M=\frac{1}{8} q L^{2}-H \Delta_{8}=0, \Delta_{8}=\frac{q L^{2}}{8 H} .
$$

The quarter-span deformation of the flexible cable is

$$
\sum M=\frac{1}{2} q\left(\frac{1}{4} L\right)^{2}-H\left(\Delta-\frac{1}{2} \Delta_{3}\right)=0, \quad \Delta=\frac{3 q L^{2}}{32 H}
$$

The quarter-span deformation of the two-hinge tensile beam is

$$
\begin{gathered}
\sum M=\frac{3}{32} q L^{2}-H \Delta_{7}-\frac{192 E I \Delta_{7}}{19 L^{2}}=0, \\
\Delta_{\rightarrow}=\frac{5 q L^{4}}{608 H L^{2}+6144 E I} .
\end{gathered}
$$

The quarter-span deformation of the three-hinge tensile beam is

$$
\Delta=\Delta_{+}+\Delta_{10}=\frac{5 q L^{4}}{160 H L^{2}+6144 E I \cos \theta}+\frac{q L^{2}}{16 H} .
$$

The mechanism displacement is

$$
\Delta_{9}=\frac{1}{2} \Delta_{8}=\frac{q L^{2}}{16 H} .
$$

The bending deformation is

$$
\begin{gathered}
P A_{10}+\frac{4_{0} \times 384 E I}{40 L^{2}}=\frac{q L^{2}}{32}, \\
\Delta_{10}=\frac{5 q L^{4}}{160 H L^{2}+6144 E I \cos \theta} .
\end{gathered}
$$

It is clear that the mid-span deformations of both the flexible cable and the three-hinge tensile beam are consistent under these two load patterns, while the two-hinge tensile beam gives a relatively small value. In addition, due to the bending stiffness of tensile beams, the quarter-span deformations of both the two-hinge tensile beam and the three-hinge tensile beam are smaller than those of the flexible cable under uniform load. Furthermore, a larger pretension results in a smaller deformation, and thus, the out-of-plane stiffness of the tensile beam is proportional to its pre-tension. Therefore, tensile beams can, in some cases, reduce deformation. Initial 
pre-tension and location of mechanism hinges have a great influence on the deformation and stress state of tensile beams.

\subsection{Distribution modes of mechanism hinges}

When the integral tow-lifting construction method is adopted, the mechanism hinges should be set at the middle of the tensile beams to make the tensile beam grid a mechanism system. According to the locations of the mechanism hinges, TBCD has seven distribution modes of mechanism hinges. Their details are listed in Table 5 and Fig. 15.

Table 5 Distribution modes of mechanism hinges

\begin{tabular}{cccc}
\hline \multirow{2}{*}{ Mode } & \multicolumn{3}{c}{ Mechanism hinge } \\
\cline { 2 - 4 } & $\begin{array}{c}\text { Middle of } \\
\text { outer TB }\end{array}$ & $\begin{array}{c}\text { Middle of } \\
\text { middle TB }\end{array}$ & $\begin{array}{c}\text { Middle of } \\
\text { inner TB }\end{array}$ \\
\hline 1 & $\mathrm{O}$ & $\mathrm{O}$ & $\mathrm{O}$ \\
2 & $\times$ & $\mathrm{O}$ & $\mathrm{O}$ \\
3 & $\times$ & $\times$ & $\mathrm{O}$ \\
4 & $\times$ & $\times$ & $\times$ \\
5 & $\times$ & $\mathrm{O}$ & $\times$ \\
6 & $\mathrm{O}$ & $\mathrm{O}$ & $\times$ \\
7 & $\mathrm{O}$ & $\times$ & $\times$ \\
\hline
\end{tabular}

$\mathrm{O}$ denotes setting mechanism hinges, $\times$ denotes no mechanism hinges, and TB is tensile beam

\subsection{Optimal distribution mode of mechanism hinges}

\subsubsection{Analysis models}

To find the characteristics of TBCD during construction, eight analysis models are built: Models I-VII are the same as Modes 1-7 shown in Figs. 15, respectively; Model VIII is a traditional cable dome. These eight models are all of the Geiger system and have the same size and initial pre-tension; they are all $60 \mathrm{~m}$ in span, $6 \mathrm{~m}$ in height, and $20 \mathrm{~m}$ in altitude at the support, with 3 pieces in the hoop, and 12 pieces in the radial direction. They all have a 0.1 rise-span ratio. Fig. 16 and Tables 6 and 7 list the component lengths and numbers, the material parameters, and the component parameters, respectively.

\subsubsection{Construction analysis}

Based on integral tow-lifting construction technology and the NDFEM form-finding method, we set lifting cables, towing cables, and oblique cables, and take the outer compressive ring as support to simulate the whole tow-lifting and tensioning pro- cess in ANSYS. The analysis cases are presented in Table 8 , where the symbol ' + ' means the added value of outer oblique cables during construction when compared with formed state.

According to the symmetry of the structures, eight sheets of towing cables, lifting cables, and

(a)

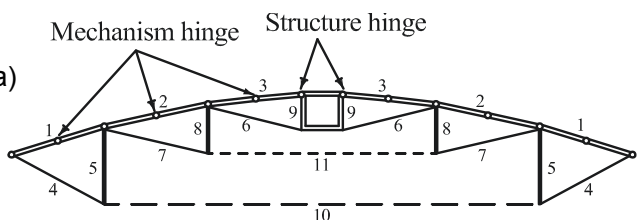

(b)

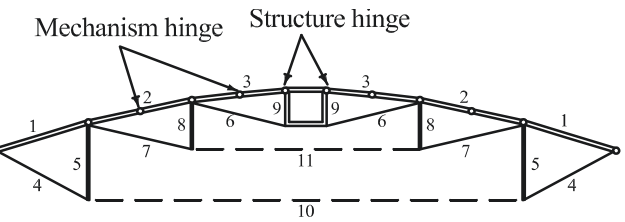

(c)

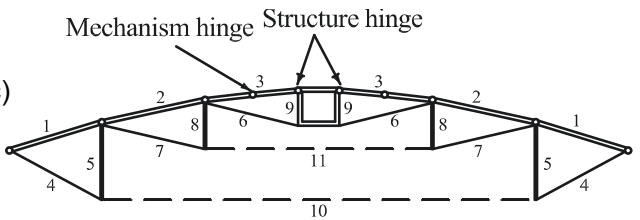

(d)

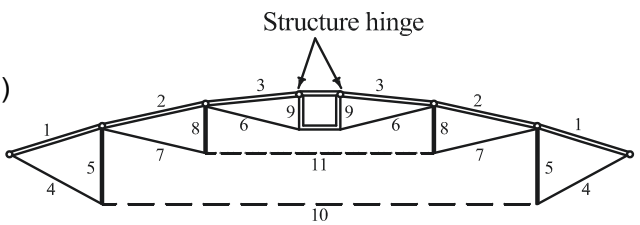

(e)

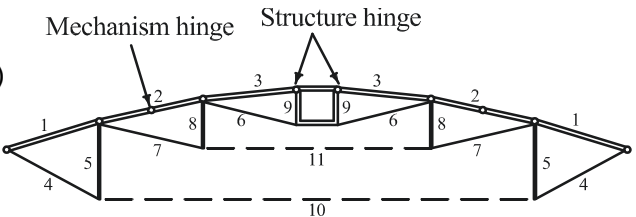

(f)

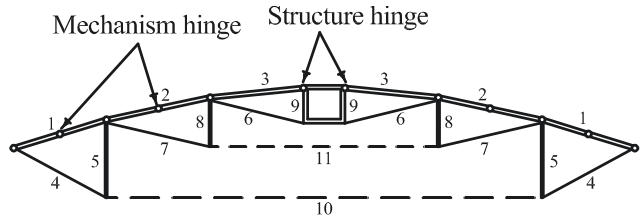

(g)

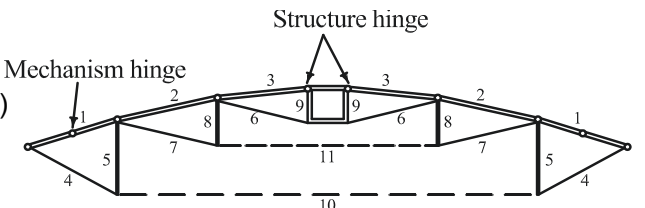

Fig. 15 Tensile-beam cable dome modes based on the distribution patterns of mechanism hinges

(a) Mode 1; (b) Mode 2; (c) Mode 3; (d) Mode 4; (e) Mode 5; (f) Mode 6; (g) Mode 7. The component numbers are the same as the ones in Fig. 8 
Table 6 Material parameters

\begin{tabular}{clccc}
\hline & Component & Type & $\begin{array}{c}\text { Density } \\
\left(\times 10^{3} \mathrm{~kg} / \mathrm{m}^{3}\right)\end{array}$ & $\begin{array}{c}\text { Elastic modulus } \\
\left(\times 10^{11} \mathrm{~N} / \mathrm{m}^{2}\right)\end{array}$ \\
\hline Traditional cable & Ridge cable & GALFAN, $1670 \mathrm{MPa}$ & 7.85 & 1.60 \\
dome & Ring cable and oblique cable & GALFAN, 1670 MPa & 7.85 & 1.60 \\
& Strut and inner tensile ring & Q345B & 7.85 & 2.06 \\
\hline Three-hinge & Tensile beam & Q420 & 7.85 & 2.06 \\
TBCD & Ring cable and oblique cable & GALFAN, 1670 MPa & 7.85 & 1.60 \\
& Strut and inner tensile ring & Q345B & 7.85 & 2.06 \\
\hline
\end{tabular}

Table 7 Component specification, element type, and initial pre-tension

\begin{tabular}{|c|c|c|c|c|c|}
\hline \multirow{2}{*}{ Component number } & \multicolumn{2}{|c|}{ Component specification (mm) } & \multicolumn{2}{|c|}{ Element type } & \multirow{2}{*}{$\begin{array}{c}\text { Initial pre-tension } \\
(\mathrm{kN})\end{array}$} \\
\hline & Model I & Model II & Model I & Model II & \\
\hline 1 & $\Phi 75$ & $\Phi 273 \times 16$ & Link10 & Beam188 & 1664 \\
\hline 2 & $\Phi 60$ & $\Phi 245 \times 12$ & Link10 & Beam188 & 1036 \\
\hline 3 & $\Phi 45$ & $\Phi 168 \times 10$ & Link10 & Beam188 & 764 \\
\hline 4 & $\Phi 75$ & $\Phi 75$ & Link8 & Link8 & 1578 \\
\hline 5 & $\Phi 180 \times 8$ & $\Phi 180 \times 8$ & Link8 & Link8 & -494 \\
\hline 6 & $\Phi 80$ & $\Phi 80$ & Link8 & Link8 & 2132 \\
\hline 7 & $\Phi 60$ & $\Phi 60$ & Link8 & Link8 & 627 \\
\hline 8 & $\Phi 60$ & $\Phi 60$ & Link8 & Link8 & 1131 \\
\hline 9 & $\Phi 168 \times 6$ & $\Phi 168 \times 6$ & Link8 & Link8 & -226 \\
\hline 10 & $\Phi 45$ & $\Phi 45$ & Link8 & Link8 & 267 \\
\hline 11 & $\Phi 140 \times 6$ & $\Phi 140 \times 6$ & Link8 & Link8 & -85 \\
\hline
\end{tabular}

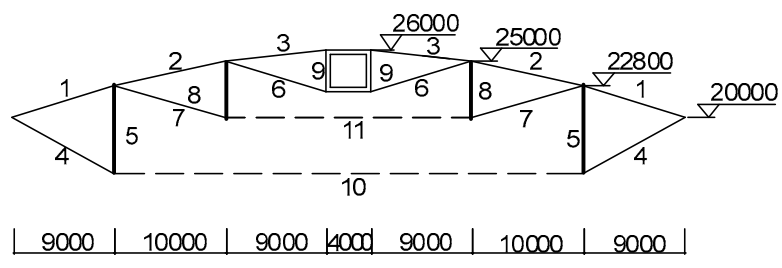

Fig. 16 Component lengths and numbers of numerical models (unit: mm)

1: outer ridge cable; 2 : middle ridge cable; 3 : inner ridge cable; 4: outer oblique cable; 5: outer strut; 6 : inner oblique cable; 7: middle oblique cable; 8: middle strut; 9: inner tensile ring; 10: outer ring cable; 11 : inner ring cable

oblique cables are used in each model. The nodamping motion Eq. (5) is used in the NDFEM form-finding analysis, and the parameters are set to: $N_{\mathrm{ei}}=30, N_{\mathrm{ts}}=5, \Delta T(1)=0.1 \mathrm{~s}, C_{\mathrm{ts}}=1.5, U_{\mathrm{ci}}=1 \mathrm{~mm}$, $U_{\mathrm{ei}}=0.005 \mathrm{~mm}$, and $N_{\mathrm{ci}}=100$.

During the tow-lifting construction analysis, Model IV and Model VII were shown to be of bad shape and eventually collapsed. Mechanism-hinge distribution modes IV and VII are therefore not feasible. The static equilibrium configurations of the key cases are shown in Fig. 17. The force variation
Table 8 Analysis cases during tow-lifting and tensioning

\begin{tabular}{ccccc}
\hline & & \multicolumn{3}{c}{ Original length $(\mathrm{mm})$} \\
\cline { 3 - 5 } Case & & $\begin{array}{c}\text { Towing } \\
\text { cables }\end{array}$ & $\begin{array}{c}\text { Lifting } \\
\text { cables }\end{array}$ & $\begin{array}{c}\text { Oblique } \\
\text { cables }\end{array}$ \\
\hline Tow- & 1 & 16000 & 32480 & +2880 \\
lifting & 2 & 14000 & 31840 & +2880 \\
& 3 & 12000 & 31200 & +2880 \\
& 4 & 10000 & 30560 & +2880 \\
& 5 & 8000 & 29920 & +2880 \\
& 6 & 6000 & 29280 & +2880 \\
& 7 & 4000 & 28640 & +2880 \\
& 8 & 2000 & 28000 & +2880 \\
& 9 & 0 & 28000 & +2880 \\
\hline Delete & & & & \\
towing & 10 & - & - & +2880 \\
cables & & & & \\
\hline Tension & 11 & - & - & +2400 \\
outer & 12 & - & - & +1920 \\
oblique & 13 & - & - & +1440 \\
cables & 14 & - & - & +960 \\
& 15 & - & - & +480 \\
& 16 & - & - & +0 \\
\hline
\end{tabular}

curves of the outer oblique cables, lifting cables, and towing cables are shown in Figs. 18-20, respectively. The tensile beams bear a tensile force from 
pre-tension and a bending moment from dead load simultaneously. Fig. 21 lists the local deformation of the mechanism hinges, and Fig. 22 lists the bending stresses of the tensile beams.

The results are listed below.
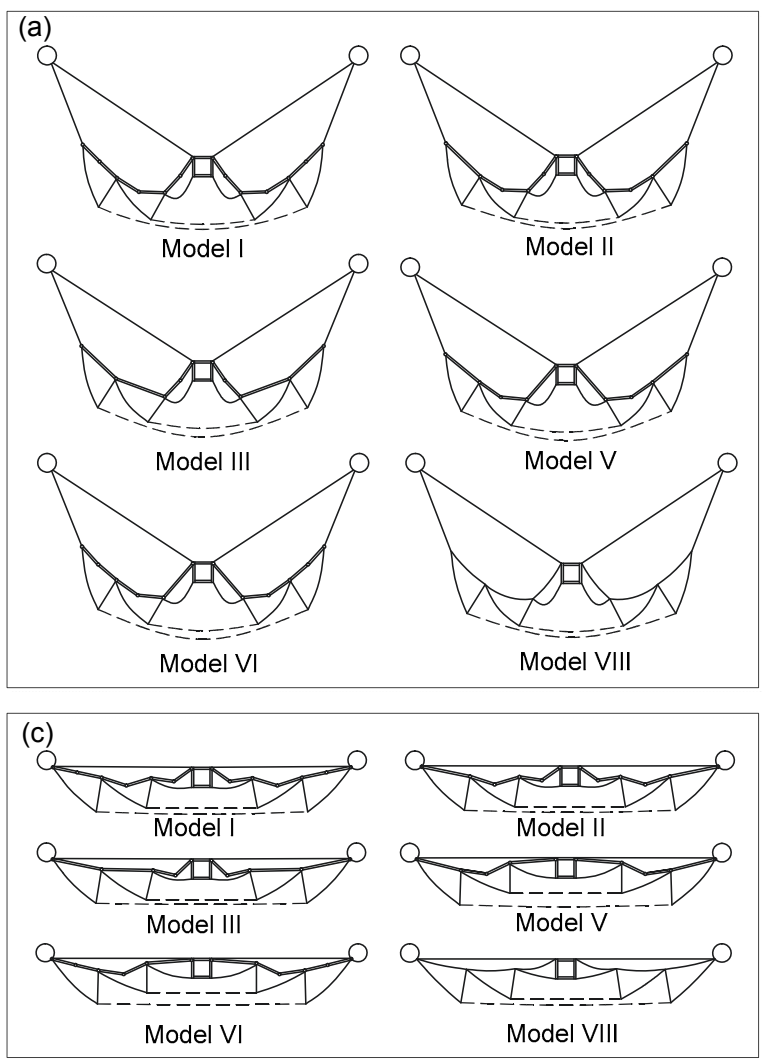

1. Feasible modes should set hinges at the middle or inner tensile beams, such as Models I/II/III/V/VI. By contrast, Models IV and VII did not complete the construction analysis with a large outof-plane deformation and large bending stress.
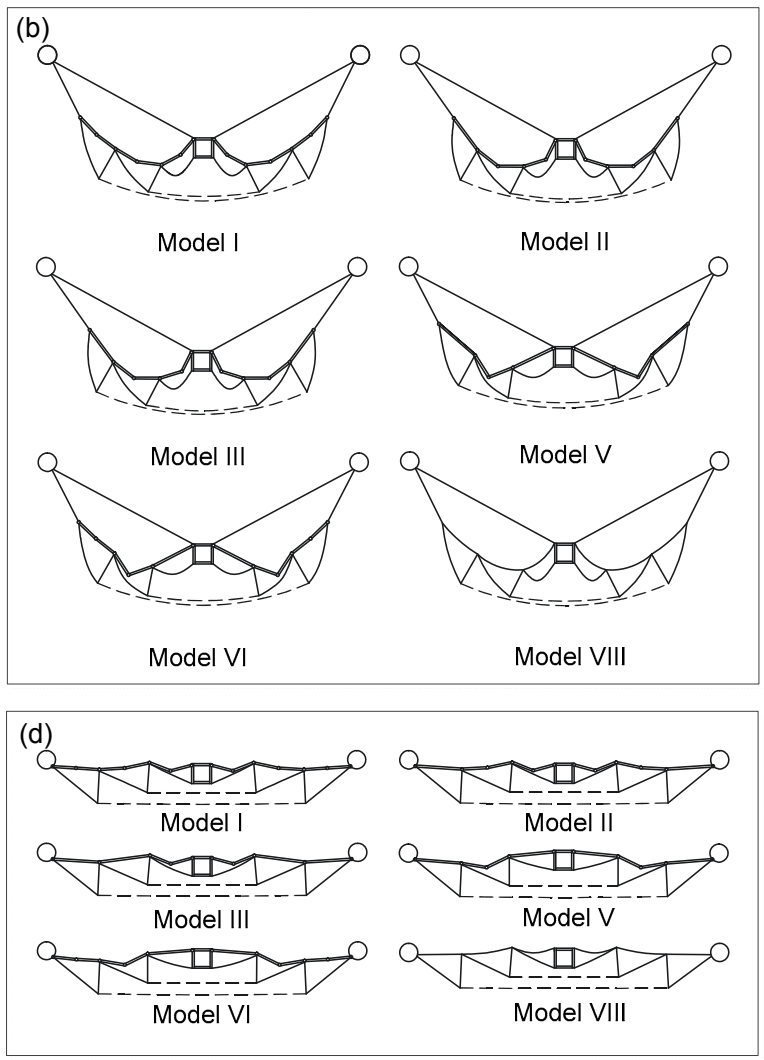

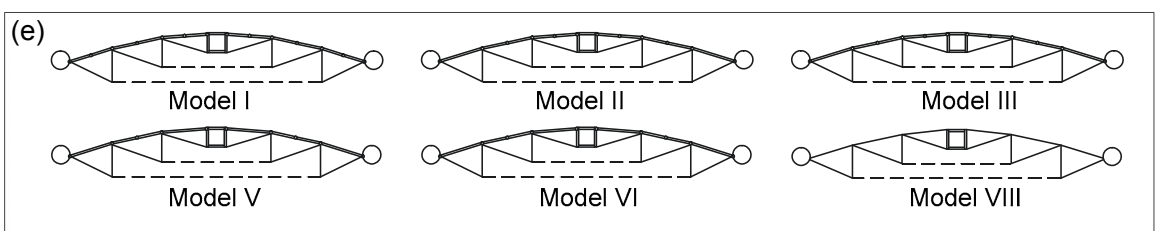

Fig. 17 Configurations of key cases in static equilibrium

(a) Case 1; (b) Case 4; (c) Case 9; (d) Case 13; (e) Case 16
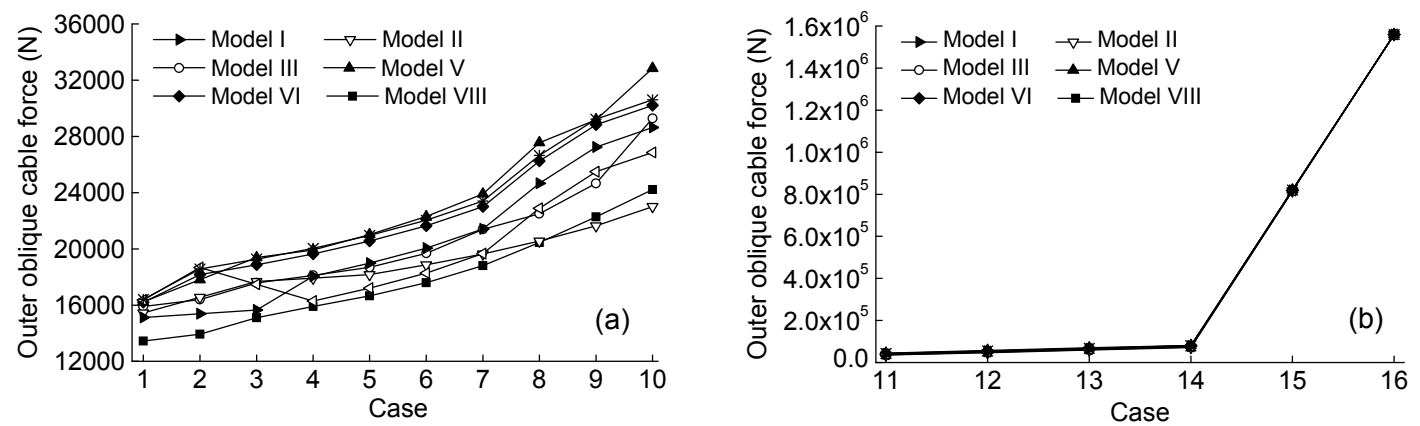

Fig. 18 Oblique cable force during construction in Cases 1-10 (a) and in Cases 11-16 (b) 


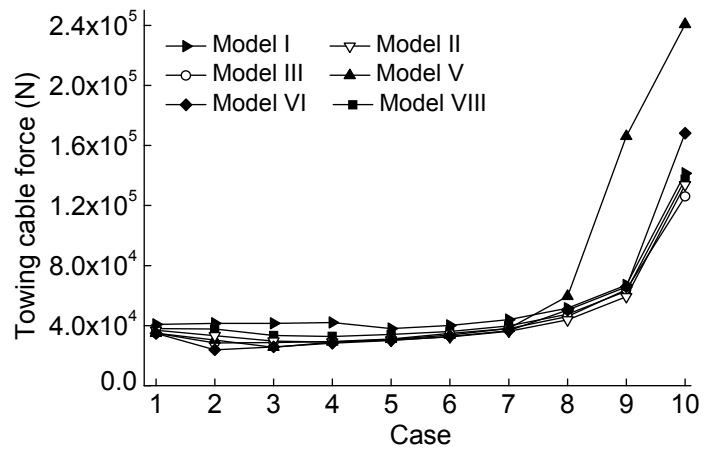

Fig. 19 Lifting cable force during construction
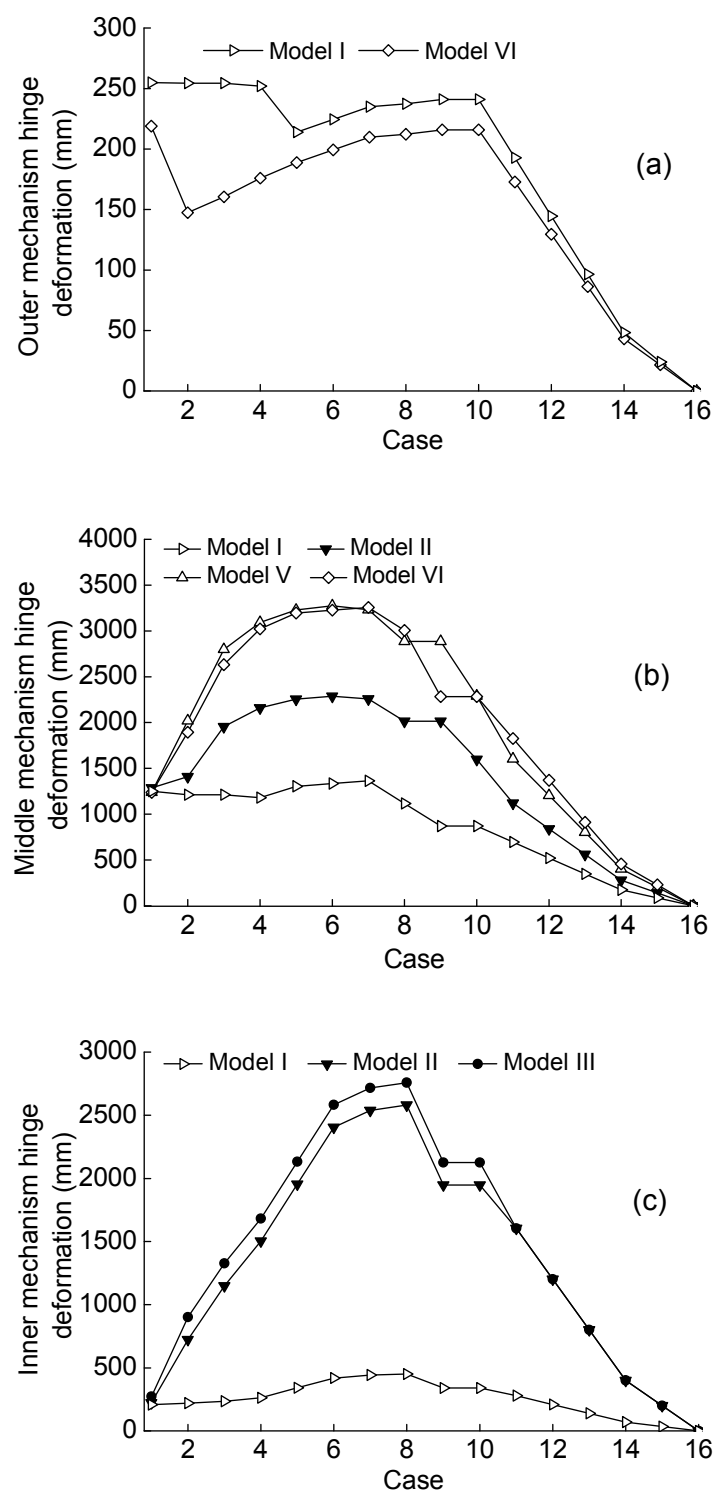

Fig. 21 Local deformation curve of mechanism hinges on outer (a), middle (b), and inner (c) tensile beams

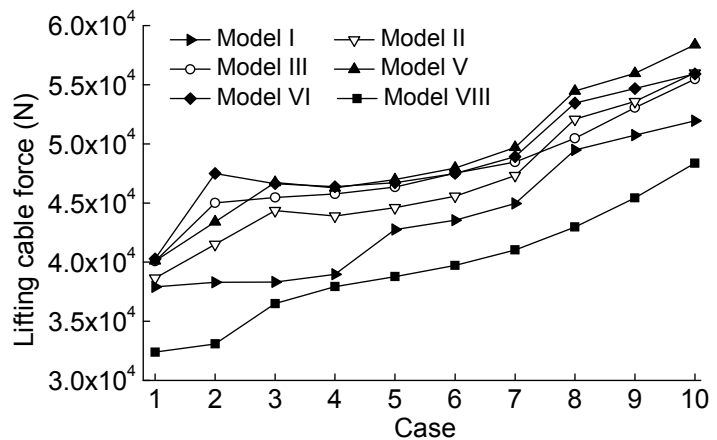

Fig. 20 Towing cable force during construction
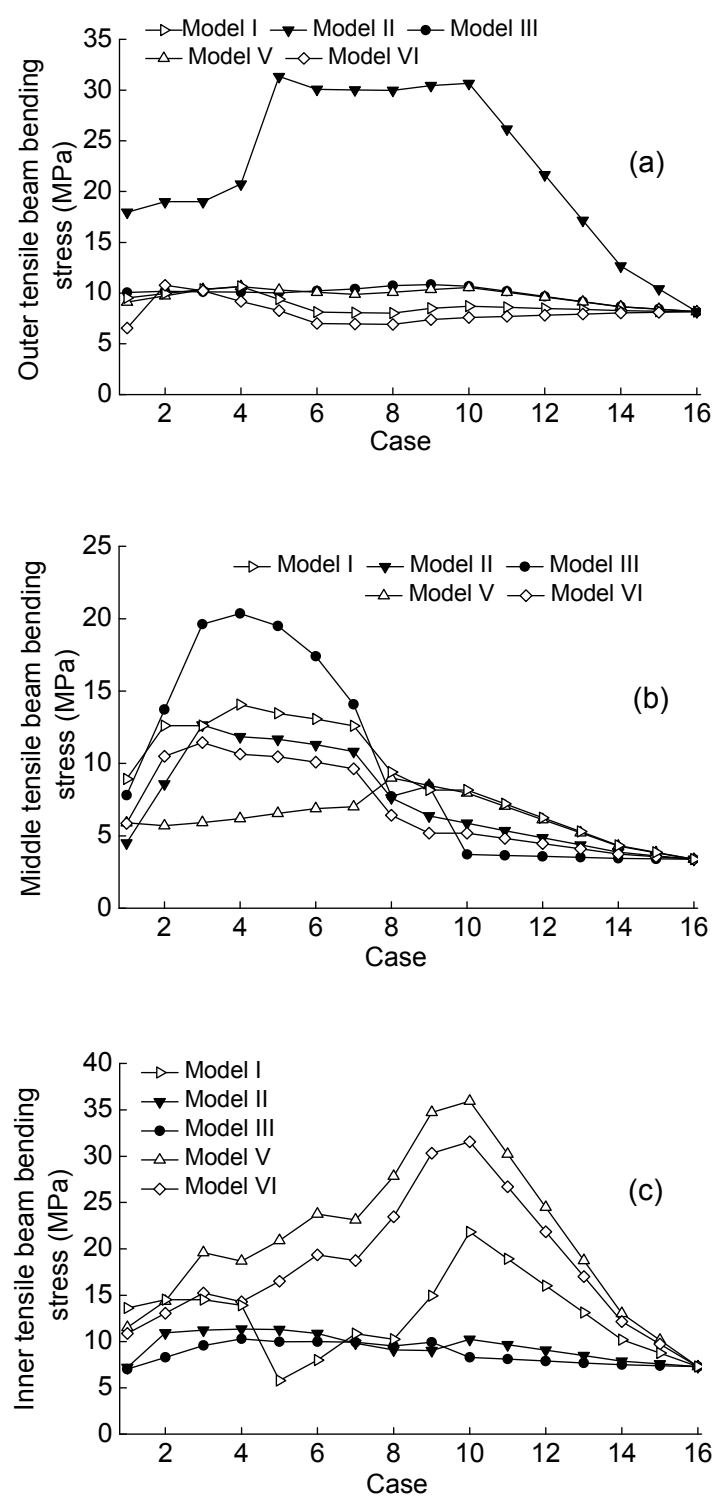

Fig. 22 Bending stress curve of outer (a), middle (b), and inner (c) tensile beams 
2. In the tow-lifting stage of Cases 1-9, the tensile-beam grid was in the " $\omega$ " shape, while cables and struts stayed hanging under the tensile-beam grid, the configurations were stable, and cable forces were relatively small.

3. During the adjusting stage of Cases 10-13, the tops of the outer and middle struts were above the outer compressive ring and the configurations changed from the hanging state to the stiffening state.

4. During the tensioning stage in Cases 14-16, the axial force of cables and tensile beams increased rapidly until the whole structure formed in Case 16.

5. In the whole process, large local deformations occurred at the hinges of tensile beams, while the bending stresses were relatively small.

6. Local deformations of the outer tensile beams were far less than those of the middle or inner tensile beams; therefore, the outer tensile beams have little influence on the overall configuration.

Furthermore, the maximum force of towing cables, lifting cables, and oblique cables are $55 \mathrm{kN}$, $23 \mathrm{kN}$, and $1578 \mathrm{kN}$, respectively. We utilized the construction equipment shown in Fig. 4 to finish this construction process. Considering safety in construction and the possibility of an unbalanced force between two jacks in one set of equipment, we set the minimum bearing capacity magnification as 2.0 .

The specifications of jacks and steel strands are listed in Table 9, in which the tensile strength, the ultimate bearing capacity, the nominal load-bearing capacity, the elastic modulus, and the density of $\Phi^{\mathrm{s}} 15.24$ steel strand are $1860 \mathrm{MPa}, 260 \mathrm{kN}, 130 \mathrm{kN}$, $2.0 \times 10^{11} \mathrm{~N} / \mathrm{m}^{2}$, and $7.85 \times 10^{3} \mathrm{~kg} / \mathrm{m}^{3}$, respectively. We chose $130 \mathrm{kN}$ as the bearing capacity of each steel strand.

6.3.3 Optimal distribution mode of mechanism hinges

By considering the influence of local deformation, the number of mechanism hinges, and the bending stress of tensile beams in sequence, the optimal distribution mode was selected from the feasible modes by an exclusive method.

At first, local deformations of outer tensile beams in Model I and Model VI were relatively small during construction, so that the mechanism hinges of the outer tensile beams may be deleted, and Model I/VI should be excluded. In addition, there were more mechanism hinges in Model II than in Model III or Model V, which will increase the complexity in construction and cost more. Thus, Model II should be excluded. Therefore, the mode with mechanism hinges set only on the inner tensile beams (Model III) and the one with mechanism hinges set only on the middle tensile beams (Model V) were equally optimal.

Table 9 Specifications of jacks and steel strands

\begin{tabular}{|c|c|c|c|}
\hline \multirow{2}{*}{$\begin{array}{c}\text { Component } \\
\text { name }\end{array}$} & \multicolumn{2}{|c|}{ Specification } & \multirow{2}{*}{$\begin{array}{c}\text { Bearing } \\
\text { capacity } \\
(\mathrm{kN})\end{array}$} \\
\hline & $\begin{array}{l}\text { Hydraulic } \\
\text { jack }(\mathrm{kN})\end{array}$ & Steel strand & \\
\hline $\begin{array}{c}\text { Towing } \\
\text { tool cable }\end{array}$ & $2 \times 200$ & $2 \times \Phi^{\mathrm{s}} 15.24$ & 260 \\
\hline $\begin{array}{l}\text { Lifting tool } \\
\text { cable }\end{array}$ & $2 \times 200$ & $2 \times \Phi^{\mathrm{s}} 15.24$ & 260 \\
\hline $\begin{array}{l}\text { Oblique } \\
\text { cable }\end{array}$ & $2 \times 2000$ & $2 \times 12 \times \Phi^{\mathrm{s}} 15.24$ & 3200 \\
\hline
\end{tabular}

\section{Conclusions}

In this paper, a new structural system called the tensile beam-cable dome (TBCD) is presented. This structure exchanges the ridge cables of the traditional cable dome for hinged tensile beams. Due to the bending stiffness of these tensile beams, the tensile beam-cable dome provides enough out-of-plane stiffness and limited local deformation when compared with traditional cable domes, and the proper mechanism hinges can convert the tensile beam grid to a mechanism system during the construction process.

The integral tow-lifting construction technology for TBCD was applied. This method uses the outer compressive ring as tow-lifting brackets. The small lifting force, limited high-level work, and high efficiency of tensioning make this method convenient. Verified by a model experiment, this method could fulfill the configuration and force requirements, with the benefits of stability and high efficiency.

In addition, to simulate the large difference of configuration between different construction stages, the NDFEM for form-finding analysis was proposed. The whole construction process was divided into several static cases, and the dynamic process was transformed to static equilibrium states during the analysis. 
By comparing the configurations of different numerical models during construction analysis, the feasible distribution modes of mechanism hinges were calculated and compared; the optimal modes will reduce both the complexity and the cost of the structure.

As a natural extension of this research, the study of tensile beam-cable domes can be extended and generalized for various categories of tensegrity structures, such as the Levy dome, the Kiewitt dome, the cable net, the cable truss, etc. This generality of the methods proposed in this paper needs to be verified by further work.

\section{References}

Ario, I., Nakazawa, M., Tanaka, Y., et al., 2013. Development of a prototype deployable bridge based on origami skill. Automation in Construction, 32:104-111. [doi:10. 1016/j.autcon.2013.01.012]

Barnes, M., 1999. Form finding and analysis of tension structures by dynamic relaxation. International Journal of Space Structures, 14(2):89-104. [doi:10.1260/02663519 91494722]

Belevičius, R., Jatulis, D., Šešok, D., 2013. Some insights on the optimal schemes of tall guyed masts. Journal of Civil Engineering and Management, 19(5):749-758. [doi:10. 3846/13923730.2013.817480]

Cai, J., Xu, Y., Feng, J., et al., 2013. Design and analysis of a glass roof structure. The Structural Design of Tall and Special Buildings, 22(8):677-686. [doi:10.1002/tal.721]

Dong, S.L., Luo, Y.Z., 2002. Nonlinear force method analysis for space truss with mobile mechanisms. Acta Mechanica Solida Sinica, 3:004 (in Chinese).

Fuller, R.B., 1975. Synergetics. Pacific Tape Library, New York, USA, p.372-434.

Gao, B.Q., Weng, E.H., 2004. Sensitivity analyses of cables to suspen-dome structural system. Journal of Zhejiang University-SCIENCE, 5(9):1045-1052. [doi:10.1631/ jzus.2004.1045]

Geiger, D.H., Stefaniuk, A., Chen, D., 1986. The design and construction of two cable domes for the Korean Olympics. Proceeding of the IASS Symposium on Shells, Membranes and Space Frames, 2:265-272.

Guo, Z.X., Zong, Z.L., Luo, B., et al., 2010a. Cable Dome Construction Method of Tower Lifting and Cable-strut Accumulative Assembly. China Patent ZL2008102343 62.1 (in Chinese).

Guo, Z.X., Luo, B., Yang, J., et al., 2010b. Key construction technology of rigid roof cable dome and engineering application. Construction Technology, 8:020 (in Chinese).

Hangai, Y., Wu, M., 1999. Analytical method of structural behaviours of a hybrid structure consisting of cables and rigid structures. Engineering Structures, 21(8):726-736. [doi:10.1016/S0141-0296(98)00027-3]

Juozapaitis, A., Kutas, R., Jatulis, D., 2008. Mast behaviour analysis and peculiarities of numerical modelling. Journal of Civil Engineering and Management, 14(1):61-66. [doi:10.3846/1392-3730.2008.14.61-66]

Kmet, S., Mojdis, M., 2013. Time-dependent analysis of cable domes using a modified dynamic relaxation method and creep theory. Computers \& Structures, 125:11-22. [doi:10.1016/j.compstruc.2013.04.019]

Kmet, S., Mojdis, M., 2015. Time-dependent analysis of cable nets using a modified nonlinear force-density method and creep theory. Computers \& Structures, 148:45-62. [doi:10.1016/j.compstruc.2014.11.004]

Levy, M.P., 1994. The Georgia Dome and beyond: achieving lightweight-longspan structures. Spatial, Lattice and Tension Structures: Proceedings of the IASS-ASCE International Symposium, Atlanta, USA, p.560-562.

Li, K., Chen, J., Xiao, Z., et al., 2003. An electrohydraulic system for synchronized roof erection. Automation in Construction, 12(1):29-42. [doi:10.1016/S0926-5805 (02)00038-9]

Luo, B., 2010. Nonlinear Dynamic FEM for Finding Static Equilibrium State of Cable-strut System. China Patent ZL200910032743.6 (in Chinese).

Luo, B., Guo, Z.X., 2012. A Kind of Sub Cable-net Cable Dome. China Patent ZL201110112593.7 (in Chinese).

Luo, B., Guo, Z.X., Gao, F., 2012. Research on non-bracket tow-lifting construction technology and complete process analysis of cable dome. Journal of Building Structures, 5:004 (in Chinese).

Luo, Y.Z., Shen, Y.B., 2004. Initial configuration determination of cable dome structure and analysis of its configuration process. Journal of Zhejiang University (Engineering Science), 38(10):1321-1327 (in Chinese).

Masic, M., Skelton, R.E., Gill, P.E., 2005. Algebraic tensegrity form-finding. International Journal of Solids and Structures, 42(16-17):4833-4858. [doi:10.1016/j.ijsolstr. 2005.01.014]

Motro, R., Najari, S., Jouanna, P., 1987. Static and dynamic analysis of tensegrity systems. In: Shell and Spatial Structures: Computational Aspects. Springer Berlin Heidelberg, p.270-279. [doi:10.1007/978-3-642-83015-0_ 24]

Ohsaki, M., Kanno, Y., 2003. Form-finding of cable domes with specified stresses by using nonlinear programming. Proceedings of IASS-APCS, Taipei, China.

Schek, H.J., 1974. The force density method for form finding and computation of general networks. Computer Methods in Applied Mechanics and Engineering, 3(1):115134. [doi:10.1016/0045-7825(74)90045-0]

Shen, Z.Y., Zhang, L.X., 2002. Simulation of erection procedures of cable domes based on nonlinear FEM. Chinese Journal of Computational Mechanics, 4:016 (in Chinese).

Vassart, N., Motro, R., 1999. Multiparametered formfinding method: application to tensegrity systems. International Journal of Space Structures, 14(2):147-154. [doi:10. 1260/0266351991494768]

Vizotto, I., 2010. Computational generation of free-form 
shells in architectural design and civil engineering. $\mathrm{Au}$ tomation in Construction, 19(8):1087-1105. [doi:10. 1016/j.autcon.2010.09.004]

Wang, Z., Yuan, X., Dong, S., 2010. Simple approach for force finding analysis of circular Geiger domes with consideration of self-weight. Journal of Constructional Steel Research, 66(2):317-322. [doi:10.1016/j.jcsr.2009. 09.010]

Xu, B., Cheng, M., Yang, H., et al., 2014. An automatic three-dimensional loading apparatus for static tests of truss joints. Automation in Construction, 48:11-17. [doi:10.1016/j.autcon.2014.08.005]

Zhang, J.Y., Ohsaki, M., 2006. Adaptive force density method for form-finding problem of tensegrity structures. International Journal of Solids and Structures, 43(1819):5658-5673. [doi:10.1016/j.ijsolstr.2005.10.011]

Zhang, L.M., Chen, W.J., Dong, S.L., 2007. Initial pre-stress finding procedure and structural performance research for Levy cable dome based on linear adjustment theory. Journal of Zhejiang University-SCIENCE A, 8(9):13661372. [doi:10.1631/jzus.2007.A1366]

\section{中文概要}

题 目: 拉梁式索穹顶累积牵引提升施工技术研究

目 的: 常规索穹顶结构具有受预应力影响较大、不易 于铺设刚性屋面等缺陷, 且施工过程中存在变 形较大及拉索松垂等问题, 施工模拟难度较
大。本文探讨一种新型索穹顶结构的构件性能 和受力特点, 研究结构施工过程分析的可行性 及最优布置形式。

创新点：1. 提出一种易于铺设刚性屋面的新型拉梁式索 穹顶结构; 2. 提出一种累积牵引提升施工技 术; 3 . 通过非线性动力有限元找形分析方法 (NDFEM) 实现施工模拟过程。

方 法: 1. 通过试验分析, 证明 NDFEM 法可以实现拉 梁式索穹顶的施工过程模拟 (图 11-13 和表 4); 2. 通过理论推导, 对比两铰拉梁、三铰拉 梁以及县索单元在跨中集中荷载和均布荷载作 用下的变形和受力特点 (公式 9-17); 3. 通过数 值模拟分析, 运用累积牵引提升施工方法 (图 4) 在施工过程分析中对机构铰的布置形式进行 可行性研究, 并提出最优分布模式。

结 论: 1. 不同于常规索穹顶结构只受拉力的脊索, 拉 梁可以同时承受拉力与弯矩, 并且弯曲应力较 小，不易失稳； 2. 整体牵引提升可以很好地完 成拉梁式索穹顶结构的施工成型过程; 在此过 程中应设置合理的机构铰将拉梁网格转化为机 构; 3. NDFEM 找形分析方法能够有效跟踪分析 施工全过程, 分析精度较高; 4. 仅在中拉梁或 内拉梁上布置机构铰可以在保证结构性能的同 时最大限度地减少后期施工的工作量, 为最优 铰节点分布模式。

关键词：拉梁式索穹顶; 整体张拉提升施工方法; 施工 分析; 机构铰 